\title{
DE PANIZZE AO RDA: UM ESTUDO SOBRE A EVOLUÇÃO DA CATALOGAÇÃO NOS CURSOS DE BIBLIOTECONOMIA NO BRASIL
}

\author{
Orientando: Eraldo Isídio Pereira Júnior \\ Graduado em Biblioteconomia \\ Orientador: $\operatorname{Prof}^{a} \operatorname{Dr}^{a}$. Edna Gomes Pinheiro \\ Doutora em Ciência da Informação \\ Professora do DCI/UFPB \\ ednagomespi@yahoo.com.br
}

\begin{abstract}
Resumo
Enfatiza que a catalogação existe desde a antiguidade, assim sendo é uma atividade indispensável para as unidades de informação. Este processo auxilia o usuário na recuperação do seu objeto de desejo para saciar sua lacuna informacional, seja por meio de fichas catalográficas, ou por sistemas automatizados. Afirma que é imprescindível a padronização da catalogação, por meio de regras e instrumentos arquétipos, que são conhecidos como códigos, que foram construídos de forma que, aceitos internacionalmente, auxiliam e orientam o trabalho da catalogação. Mostra a preocupação em conhecer como os Cursos de Graduação em Biblioteconomia no Brasil estão tratando essa questão, haja vista que a diversidade de recursos informacionais e de suportes disponíveis na organização e tratamento da informação têm levado a refletir sobre a necessidade de revisar métodos de ensino e instrumentos utilizado pelos cursos, responsáveis pela formação do profissional bibliotecário. Tem como objetivo geral: mapear as ementas da disciplina Representação Descritiva da Informação, dos Cursos de Biblioteconomia no Brasil, no intuito de revelar a articulação da catalogação aos novos formatos bibliográficos (MARC, RDA, FRBR, Dublin Core). Se caracteriza como uma pesquisa virtual realizada nos sites de universidades brasileiras, especificamente, nos sites dos Cursos de bacharelado em biblioteconomia. Constata a ausência de uma terminologia única em relação a disciplina em questão. E, ainda, que os Cursos de Biblioteconomia no Brasil, ainda estão se adequando as mudanças advindas da tecnologia da informação que estão consolidam a catalogação cooperativa.
\end{abstract}

Palavras-Chave: Representação descritiva da informação. Ensino de Biblioteconomia 